\title{
Review
}

\section{The role of infection in acute pancreatitis}

Acute pancreatitis can be a mild, transitory illness or a severe, rapidly fatal disease. About $80 \%$ of cases of the disease are acute interstitial oedematous pancreatitis which has a low morbidity and mortality rate $(<1 \%)$ and roughly $20 \%$ of patients with acute pancreatitis develop necrosis of pancreatic and peripancreatic tissues. The course of severe acute pancreatitis may include an early vasoactive and toxic phase, and a late period dominated by septic complications. Improved intensive care treatment can reduce the early cardiorespiratory and renal complications related to systemic inflammatory response syndrome (SIRS). ${ }^{2}$ Pancreatic infection is reported to develop in $40-70 \%$ of patients with necrotising pancreatitis and is the main life threatening complication of the disease; furthermore, consecutive sepsis and sepsis related multiple organ failure are responsible for a mortality rate of up to $50 \% .^{3-5}$ In the early phase of acute pancreatitis, a broad range of specific treatment modalities have been evaluated, but all have proved ineffective. $^{6-8}$ Therefore, interest has focussed on the prophylactic administration of antibiotics. The use of antibiotic treatment is based on the rationale that reduction of pancreatic infection will decrease late morbidity and mortality. However, the beneficial effects of antibiotic prophylaxis are still controversial.

\section{Possible pathways for pancreatic infection}

There are several hypothetical mechanisms by which bacteria may enter pancreatic and peripancreatic necrosis (fig 1): the haematogenous route via the circulation $^{910}$; transmural migration through the colonic bowel wall either to the pancreas (translocation), ${ }^{11}$ via ascites to the pancreas, ${ }^{912}{ }^{13}$ or via the lymphatics to the circulation ${ }^{12}{ }^{14}$; via the biliary duct system ${ }^{15}{ }^{16}$; from the duodenum via the main pancreatic duct. ${ }^{117}$

Animal studies have shown spontaneous bacterial infection of the pancreas. ${ }^{19}$ In healthy animals, immunocompetent cells usually clear these contaminating organisms. However, stress, such as acute inflammation, renders the pancreas vulnerable to bacterial infection; the intestinal

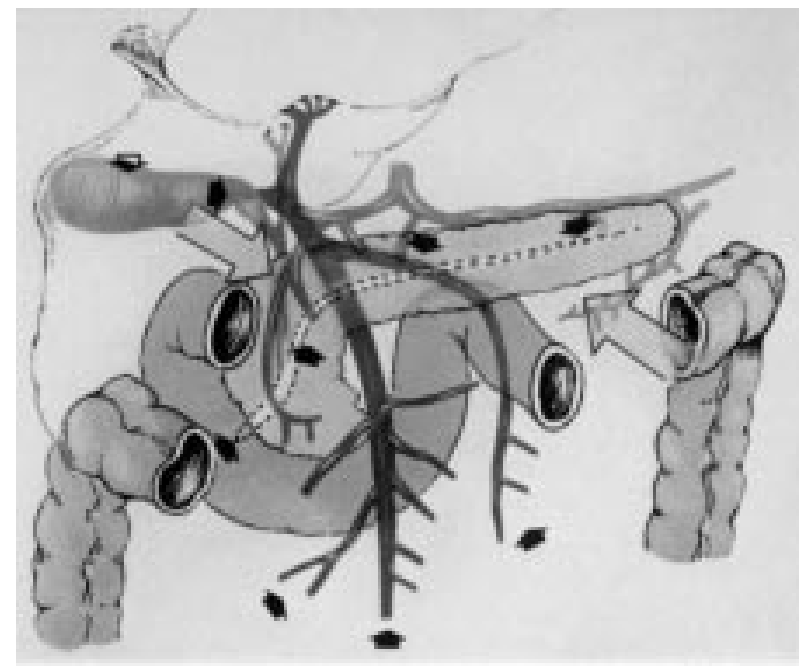

Figure 1 Possible infection routes in severe acute pancreatitis. ${ }^{18}$ mucosal barrier fails, allowing these organisms to translocate to mesenteric lymph nodes, the systemic circulation, the portal venous circulation, the peritoneal cavity, and abdominal organs, with resulting supervening sepsis and critical complications. As most pathogens in pancreatic infection are gastrointestinal Gram negative bacteria, the colon seems to be the main source of pancreatitis related infections. It is, therefore, possible that bacterial translocation is the most important mechanism for contamination of pancreatic necrosis. However, considerable controversy exists about the exact pathway: do bacteria enter the pancreas after colonic translocation, through the lymphatics and circulation via contaminated ascites, or do they migrate directly to the inflamed gland because of the proximity of the transverse colon to the pancreas?

Experimental studies provide equivocal results. From their study of caerulein induced acute pancreatitis in rats, Medich et al concluded that acute pancreatitis promotes bacterial translocation leading to transperitoneal infection of the pancreas, and suggested that selective decontamination of the gut, and peritoneal lavage, may prevent pancreatic infection in acute pancreatitis. ${ }^{20}$ This view is supported by Marotta et al who found that ascites were the most frequently infected sample in a model of acute pancreatitis, induced by an intrabiliary injection of a trypsin/ enterokinase mixture. ${ }^{13}$ In contrast, a recent study by Arendt et al indicated that bacteria do not spread from the peritoneal cavity in caerulein induced acute pancreatitis in rats. They showed that the peritoneal cavity could obstruct bacteria, rather than act as a source of bacterial seeding. ${ }^{21}$ Further experiments by Widdison et al supported the hypothesis that infection of pancreatic necrosis occurs transmurally from the colon to the pancreas; they showed that enclosing the colon in an impermeable bag prevented infection of pancreatic necrosis in a necrotising model of acute pancreatitis. ${ }^{11}$

The mechanism of bacterial translocation in human necrotising pancreatitis is still a matter of considerable debate as conclusions drawn from animal studies may not be directly transferable. Additionally, human studies to evaluate translocation are difficult to perform in an ethical manner. However, many clinical studies suggest that systemic infections and multiple organ failure in critically ill or injured patients often originate from intestinal floral migration, possibly via failure of the intestinal barrier. ${ }^{22}{ }^{23} \mathrm{~A}$ recent investigation of pancreatic infection by Luiten et al provided clinical evidence that aerobic Gram negative intestinal bacterial organisms are linked to a significantly increased risk of Gram negative pancreatic infections. ${ }^{24}$

In summary, the most probable source of pancreatic infection seems to be the colon via bacterial translocation. However, the exact route of post bacterial transmural migration is still unknown. Possible pathways are via the lymphatics and consecutive haematogenous spread, or transmurally to the pancreas.

Abbreviations used in this paper: CRAI, continuous regional arterial perfusion; CT, computed tomography; MIC, minimal inhibitory concentration; SIRS, systemic inflammatory response syndrome; SDD, selective decontamination of the digestive tract. 
Table 1 Correlation of extent of necrosis on contrast enhanced computed tomography scanning and infection rate in patients with severe acute pancreatitis (adapted from ${ }^{18}$ )

\begin{tabular}{lll}
\hline Extent of necrosis & Sterile $(n=155)$ & Infected $(n=71)$ \\
\hline$<30 \%$ & 57 & 35 \\
$>30$ to $<50 \%$ & 22 & 23 \\
$>50 \%$ & 21 & 42 \\
\hline
\end{tabular}

Clinical significance of infected pancreatic necrosis The Atlanta symposium classification ${ }^{25}$ of severe acute pancreatitis links it to organ failure and/or local complications, including necrosis, abscess, or pseudocysts. Usually, pancreatic infection is linked to the development of pancreatic necrosis, which is defined as either a diffuse or focal area of non-viable pancreatic parenchyma, and is typically associated with peripancreatic fatty tissue necrosis. A pancreatic abscess is a consequence of severe acute pancreatitis and is a circumscribed intra-abdominal collection of pus, usually in the proximity of the pancreas and containing little or no pancreatic necrosis. It is likely that pancreatic abscesses are a consequence of limited necrosis, with subsequent liquification and secondary infection during the course of severe acute pancreatitis. A postacute pseudocyst is pancreatic juice, enclosed by a wall of fibrous or granulated tissue, which may develop in severe acute pancreatitis; bacteria may be present.

Several studies have examined the frequency of bacterial infection of necrotic areas in the natural course of severe acute pancreatitis, without antibiotic intervention. ${ }^{52627}$ Beger et al showed an overall contamination rate of $24 \%$ within the first week of the onset of acute pancreatitis in patients undergoing surgery for severe acute pancreatitis, increasing to 46 and $71 \%$, respectively, in the second and third weeks. ${ }^{5}$ Thus, patients with severe acute pancreatitis have the highest risk of pancreatic infection in the third week after onset of the disease. The overall infection rate in this series was $39 \%$. Similar results were reported by Gerzof et al who performed percutaneous computed tomography (CT) guided aspiration and Gram staining, and by Bassi et al who examined smears taken intra-operatively. However, the frequency of pancreatic infection was higher in these studies, with rates of $60 \%$ and $63 \%$, respectively. ${ }^{26}{ }^{27}$

Pancreatic necrosis usually becomes infected at a late stage in the disease, and is dependent on the extent of intraand extra-pancreatic necrosis. ${ }^{52-30}$ Through morphological analysis by contrast enhanced CT scanning, Beger et al found a higher rate of infection in patients with extensive pancreatic necrosis. Two thirds of the patients with infected pancreatic necrosis had a total amount of necrosis of more than $30 \%$, whereas $60 \%$ of patients with sterile necrosis had necrotic areas of less than $30 \%$ (table 1 ). ${ }^{31}$ Therefore, it seems that the presence of a significant extent of necrosis ( $>50 \%$ on CT scanning) is predictive of severe disease, and helps to identify patients who might develop septic complications. ${ }^{32} 33$

The influence of bacterial infection on morbidity and mortality in severe acute pancreatitis has been analysed in surgically treated patients with infected pancreatic necrosis and in patients with sterile necrosis who have had surgery. ${ }^{5}$ This study looked at 170 patients with severe acute pancreatitis. Of these, $42 \%$ had infected pancreatic necrosis and $58 \%$ had sterile necrosis. Preoperative morbidity in the group with infected pancreatic necrosis was significantly higher than in patients with sterile necrosis with respect to pulmonary $(56 \% v 72 \%)$, renal $(28 \% v 45 \%)$, and cardiocirculatory $(13 \%$ v $30 \%)$ insufficiency. The mortality rate in the infected group was $20 \%$ (14 of 71

Table 2 Bacteriology in severe acute pancreatic; $n=87$ patients (adapted from ${ }^{562753}$ )

Escherichia coli

Staphylococcus aureus

Pseudomonas spp

Klebsiella spp

Proteus spp

Candida

Streptococcus faecalis

Enterobacter spp

Anaerobes

$25 \%$

$7 \%$

$15 \%$

$9 \%$

$4 \%$

$3 \%$

$3 \%$

$16 \%$

Monomicrobial

$76 \%$

Polymicrobial

$24 \%$

patients), a figure significantly higher than in the sterile group ( $11 \%$; 10 of 99 patients).

In summary, infected pancreatic necrosis is a significant prognostic factor in severe acute pancreatitis. As infection is the leading cause of morbidity and mortality from acute pancreatitis, diagnosis and optimal treatment of infectious complications is vital.

\section{Bacteriology in infected pancreatic necrosis}

While most complicating infections in animal pancreatic studies, hospitalised patients, and in pancreatic infection are caused by a few species of bacteria (table 2), normal intestinal flora consists of more than 400 species. ${ }^{34}$ In the natural course of severe acute pancreatitis, cultures of infected pancreatic necroses yield monomicrobial flora in $60-87 \%$ of cases; in these studies, polymicrobial flora was confirmed in only $13-40 \%$ of cases (table 2)..$^{2627} \mathrm{~A}$ preponderance of Gram negative aerobic bacteria is usually present (Escherichia coli, Pseudomonas spp, Proteus, Klebsiella spp) which suggests an enteric origin, but Gram positive bacteria (Staphylococcus aureus, Streptococcus faecalis, Enterococcus), anaerobes, and, occasionally, fungi have also been found..$^{526}$ 35-39 The incidence of fungi in long term disease may increase, especially after prolonged antibiotic treatment. ${ }^{527}$ In one study, candida infection was reported in $21 \%$ of patients with infected pancreatic necrosis. ${ }^{40}$ Luiten et al studied prospectively the difference between Gram negative and Gram positive infection in patients with infected pancreatic necrosis. ${ }^{41}$ They found that Gram negative infection was linked to a significantly higher mortality than Gram positive pancreatic infection.

\section{Prevention of infection of pancreatic necrosis}

Given the poor prognosis of patients with severe acute pancreatitis and infection, the possibility of prevention and/or treatment of pancreatic infection has received major attention. A summary of the options follows.

\section{INTRAVENOUS ANTIBIOTIC PROPHYLAXIS}

Infection of initially sterile pancreatic necrosis develops in the later stages of severe acute pancreatitis, thus effective antibiotic treatment may reduce late mortality. Three early studies of the use of prophylactic intravenous antibiotics in the treatment of unselected patients with acute pancreatitis failed to show any favourable effect on morbidity and mortality. ${ }^{42-44}$ However, most of the patients in these studies had mild acute pancreatitis with no risk of pancreatic infection. Furthermore, later studies that focussed on pancreatic tissue concentrations of antibiotics after intravenous administration showed that ampicillin, the drug used most frequently in these early trials, failed to reach therapeutic concentrations in the infected gland, or to cover the Gram negative micro-organisms present in infected pancreatic necrosis. ${ }^{45}{ }^{46}$ This altered pharmacokinetic behaviour of antibiotics is based on the observation that the pancreas has a barrier comparable to the blood-brain barrier $^{47}$; this blood-pancreas barrier is 
Table 3 Efficacy factors for different antibiotics in pancreatic tissue-for example, an efficacy factor of 1.0 would indicate that the antibiotic would inhibit all bacteria commonly found in pancreatic infection (adapted from $^{45}$ )

\begin{tabular}{ll}
\hline Antibiotic & Efficacy factor \\
\hline Aminoglycosides & \\
Netilmicin & 0.14 \\
Tobramycin & 0.12 \\
Acylureidopenicillins & 0.71 \\
Mezlocillin & 0.72 \\
Piperacillin & 0.75 \\
Cephalosporins & 0.76 \\
Cefotiam & 0.78 \\
Ceftizoxime & 0.79 \\
Cefotaxime & 0.86 \\
Ceftriaxone & 0.87 \\
Quinolones & \\
Ciprofloxacin & 0.98 \\
Ofloxacin & \\
Imipapenems & \\
\hline
\end{tabular}

responsible for the selective uptake of antibiotic drugs into the pancreas. Evaluation of the concentrations of the various classes of antibiotics has shown that the quinolones (ciprofloxacin, ofloxacin) and the carbapenem, imipenem, are substances with high pancreatic tissue concentrations and the highest bactericidal activity against most of the organisms present in pancreatic infection. ${ }^{45}$ In contrast, aminoglycosides are unable to penetrate human pancreatic tissue in bactericidal concentrations. The efficacy factors of some antibiotic classes are listed in table 3. This factor includes the type and frequency of bacteria found in infected pancreatic necrosis, antibiotic tissue concentrations, and the percentage of inhibited bacterial strains according to the minimal inhibitory concentration (MIC). Consequently, an ideal efficacy factor of 1 corresponds to complete inhibition of bacteria in infected pancreatic necrosis. Imipenem has an excellent efficacy factor of 0.98 , whereas aminoglycosides have a very low factor (0.13). Metronidazole acts exclusively against anaerobes and is recommended only in combination with non-anaerobic antibiotics.

Prophylactic treatment with imipenem, used in a randomised controlled clinical trial by Pederzoli and colleagues, reduced the incidence of pancreatic $(12.2 \% v$ $30.3 \%)$ and non-pancreatic (14.6\% v $48.5 \%)$ sepsis significantly in patients with CT proved severe acute pancreatitis. However, the overall mortality rate $(7.3 \% v$ $12.1 \%$ ), the rate of multi-organ failure, and the necessity for surgery were all unaffected (table 4 ). ${ }^{48}$ A weakness of this study is the relatively low number of patients ( 74 overall); moreover, only two of 16 patients with $>50 \%$ extent of necrosis were randomised to the control group (with a consequent bias in selection in the control group). Thus, overall mortality $(9.4 \%)$ was low and reflected a less severe disease. These results correspond with the results of Foitzik et al who found a significantly reduced rate of pancreatic infection after the application of imipenem with an unchanged mortality rate, in an animal model of severe acute pancreatitis. ${ }^{53}$

Sainio et al observed a significantly reduced mortality rate in patients with severe acute alcohol induced pancreatitis treated with cefuroxime. The reduction in mortality from $23 \%$ in the control group to $3 \%$ in the treatment group was not associated with reduced pancreatic sepsis, and probably reflected a significantly decreased frequency of infectious complications. ${ }^{49}$ However, the number of patients was low (30 $v 30$ ), cefuroxime was changed to alternative antibiotics after a mean of 9.2 days in 20 of the 30 patients in the antibiotic group, and antibiotics were started in 23 of 30 patients in the control group at a mean of 6.1 days. Although the pancreatic pharmacokinetics of cefuroxime are unknown, failure to reduce pancreatic sepsis suggests poor pancreatic penetration similarly to other second generation cephalosporins. This is in contrast to third generation cephalosporins, which achieve adequate pancreatic tissue concentrations.

The combination of ceftazidime, amikacine, and metronidazole for 10 days decreased the incidence of sepsis in patients with severe alcoholic acute pancreatitis, but no statistical differences were found for pancreatic infection and mortality. ${ }^{50}$ However, conclusions from this study should be interpreted with caution because of the low number of patients recruited $(n=23)$. Additionally, amikacine belongs to the aminoglycosides class, which do not seem to penetrate the pancreas adequately.

In a clinical controlled study using intravenous antibiotic prophylaxis with ofloxacin and metronidazole, Schwarz et al noted that the rate of Gram negative pancreatic infection in the treatment group ( $1 / 13$ patients, $7 \%)$ was lower than in the control group (6/16 patients, $46 \%) .{ }^{51}$ However, no statistically significant reduction in pancreatic infection was seen because of the low number of patients in the study.

Bassi et al also studied drug concentrations of several antibiotics in serum and samples of pancreatic necrosis. In this study, necrotic sample concentrations of metronidazole and pefloxacin, which belongs to the fluoroquinolone class, exceeded the MIC for the organisms most commonly isolated in this disease. Imipenem and mezlocillin did not have consistently high MICs; aminoglycoside concentrations were also inadequate. Repeated administration of drugs seemed to encourage pefloxacin, imipenem, and metronidazole to penetrate necrotic pancreatic tissue. ${ }^{46}$ Pefloxacin proved inferior to imipenem in the prevention of

Table 4 Prospective randomised studies of prophylactic antibiotic treatment in severe acute pancreatitis

\begin{tabular}{|c|c|c|c|c|c|c|c|c|c|}
\hline \multirow[b]{2}{*}{ Reference } & \multirow[b]{2}{*}{ Drug } & \multicolumn{2}{|c|}{ Patients (n) } & \multicolumn{2}{|c|}{$\begin{array}{l}\text { Rate of pancreatic } \\
\text { infection (\%) }\end{array}$} & \multicolumn{2}{|c|}{ Rate of MOF (\%) } & \multicolumn{2}{|c|}{ Mortality (\%) } \\
\hline & & Control & Case & Control & Case & Control & Case & Control & Case \\
\hline $\begin{array}{l}\text { Luiten and } \\
\text { colleagues }^{35}\end{array}$ & $\begin{array}{l}\text { Oral and rectal SDD/i.v. } \\
\text { cefotaxime }\end{array}$ & 52 & 50 & 38 & $18 \ddagger$ & & & 35 & 22 \\
\hline $\begin{array}{l}\text { Pederzoli and } \\
\text { colleagues }^{48}\end{array}$ & Imipenem & 33 & 41 & 30 & $12^{\star}$ & 39 & 29 & 12 & 7 \\
\hline $\begin{array}{l}\text { Sainio and } \\
\text { colleagues }^{49}\end{array}$ & Cefuroxime & 30 & 30 & 40 & 30 & & & 23 & $3 \dagger$ \\
\hline $\begin{array}{l}\text { Delcenserie and } \\
\text { colleagues }^{50}\end{array}$ & $\begin{array}{l}\text { Ceftazidime/amikacine/ } \\
\text { metro nidazole }\end{array}$ & 12 & 11 & 58 & $0 \ddagger$ & & & 25 & 9 \\
\hline $\begin{array}{l}\text { Schwarz and } \\
\text { colleagues }^{51}\end{array}$ & Ofloxacin/metronidazole & $\begin{array}{l}13 \\
\text { Pefloxacin }\end{array}$ & $\begin{array}{l}13 \\
\text { Imipenem }\end{array}$ & $\begin{array}{l}53 \\
\text { Pefloxacin }\end{array}$ & $\begin{array}{l}61 \\
\text { Imipenem }\end{array}$ & Pefloxacin & Imipenem & $\begin{array}{l}15 \\
\text { Pefloxacin }\end{array}$ & $\begin{array}{l}0 \\
\text { Imipenem }\end{array}$ \\
\hline $\begin{array}{l}\text { Bassi and } \\
\text { colleagues }^{52}\end{array}$ & Pefloxacin $v$ imipenem & 30 & 30 & 34 & $10 \ddagger$ & & & 24 & 10 \\
\hline
\end{tabular}

SDD, oral and rectal application of colistin sulphate, amphotericin, and norfloxacin; MOF, multiple organ failure.

${ }^{\star} \mathrm{p}<0.01 ; \uparrow \mathrm{p}=0.028 ; \ddagger \mathrm{p}=0.03$. 
infection associated with severe necrotising pancreatitis (extent of pancreatic necrosis $>50 \%$ ), in spite of its potential for prevention. This trial included 60 patients who were given either pefloxacin or imipenem for two weeks. The incidence of infected pancreatic necrosis in the pefloxacin and imipenem groups was $34 \%$ and $10 \%$, respectively. Imipenem proved significantly more effective in prevention of pancreatic infections $(\mathrm{p} \leqslant 0.05)$. Mortality was higher in the pefloxacin group (24\%) compared with the imipenem group $(10 \%)$, although the difference was not statistically significant (table 4$).^{52}$

In summary, only the study of cefuroxime by Sainio et al showed significantly reduced patient mortality following prophylactic treatment with antibiotics. ${ }^{49}$ Unfortunately, all prospective studies analysing antibiotic prophylaxis in acute pancreatitis have used small sample sizes. Problems with data analysis have been compounded by the negligible incidence of mortality in the control population. Thus, Golub et al performed a meta-analysis of all prospective trials in order to see whether there is a therapeutic role for antibiotics in acute pancreatitis. ${ }^{54}$ The authors found that mortality was significantly reduced in a subgroup of patients with severe pancreatitis who were given broad spectrum antibiotics.

Medical experience also supports the administration of prophylactic antibiotics as the incidence of pancreatic infection seems to have over the past 10 years. With the introduction of antibiotic prophylaxis, both Banks et al, and Ho and Frey, have reported a reduction in infected necrosis at a single institution from $67 \%$ to $32 \%$ and $76 \%$ to $27 \%$, respectively. ${ }^{39} 55$ However, patient survival has stabilised or has shown a non-significant trend to decrease.

In conclusion, no sufficiently powerful randomised controlled trial proves definitively that there is a role for prophylactic antibiotic treatment. ${ }^{56}$ However, current evidence would seem to justify early prophylactic administration of an antibiotic concentrated by the pancreas (for example, imipenem) in patients with severe acute pancreatitis. ${ }^{57}$ Further trials are urgently needed to evaluate the duration of antibiotic treatment, the administration of antibiotics alone or in combination with antimycotics, and the apparent shift in bacteria during the past two years.

\section{SELECTIVE DECONTAMINATION OF THE DIGESTIVE TRACT} (SDD)

Elimination or reduction of intestinal bacteria may reduce or eliminate infection in pancreatic necrosis. In 1984, Stoutenbeek et al reported that selective decontamination of the digestive tract with non-absorbable antibiotics, administered via a gastric tube, reduced the aerobic Gram negative intestinal flora in patients with multiple trauma. ${ }^{58}$ In combination with systemic short term cefotaxime, directed against early endogenous infection, the total infection rate decreased from $81 \%$ to $16 \%$ in their patients. Several other studies have shown that selective decontamination eliminates Gram negative bacteria from the intestinal tract, and sometimes reduces Gram negative septic complications in patients on intensive care units. However, results which show any reduction in actual mortality may be contradictory. ${ }^{59-62}$

During their hospital stay, the digestive tract of more than $60 \%$ of patients with severe acute pancreatitis is colonised with nosocomial Gram negative flora. As the risk of infection of pancreatic necrosis increases with Gram negative intestinal colonisation, elimination of these pathogens by prophylactic selective decontamination with enterally administered antibiotics is an attractive method for prevention of infection of pancreatic necrosis. Several experimental investigations have examined the use of selective decontamination in severe acute pancreatitis.
These studies have shown that reduced intestinal flora resulted in improved survival ${ }^{9}$ and, possibly, reduced pancreatic infection..$^{536364}$

In an uncontrolled clinical study, SDD reduced the infection rate and sepsis in patients with acute pancreatitis complicated by acute respiratory failure, but mortality did not change. ${ }^{65}$ Luiten et al published a randomised controlled trial investigating SDD in patients with severe acute pancreatitis, defined by an Imrie score $\geqslant 3$ and or a Balthazar grade D or E..$^{35667}$ Fifty of 102 patients were treated with oral and rectal administration of colistin sulphate, amphotericin, and norfloxacin, combined with a short term systemic prophylaxis with cefotaxime until the cultures taken orally and rectally became sterile. In patients treated with SDD the overall incidence of infected necrosis $(18 \% v 38 \%$ in the control group, $\mathrm{p}=0.03)$ and the rate of re-laparotomy (3.1 in the control group $v 0.9$ in the SDD group, $\mathrm{p}<0.05)$ was significantly reduced. Potentially, these findings can be ascribed to the notable reduction in Gram negative infected pancreatic necrosis $33 \%$ in the control group $v 8 \%$ in the SDD group; $\mathrm{p}=0.003)$. Overall mortality in patients treated with selective decontamination was not significantly reduced ( $22 \% v 35 \%$ in the control group). However, the authors suggested that SDD reduced mortality in patients with severe acute pancreatitis and an Imrie score $\geqslant 3$, regardless of the CT findings on admission. Nevertheless, the most important question remains unanswered: were the positive results in the treatment group achieved by topical treatment with SDD or by the short term application of intravenous antibiotics?

INTRA-ARTERIAL ANTIBIOTIC PROPHYLAXIS

Few data exist about the efficacy of continuous regional arterial perfusion (CRAI). Habashi et al studied intravenously or intra-arterially administrated antibiotics in bile induced acute pancreatitis in dogs. CRAI of antibiotics decreased the serum concentrations of endotoxin and phospholipase A2 activity, and completely prevented the occurrence of pancreatic infection; it also significantly improved the survival rate in the test animals. ${ }^{68}$ Unfortunately, the conclusions of this study are limited by the length of follow up ( 36 hours). In another study, Takeda et al examined the CRAI of nafamostat, a protease inhibitor, in combination with antibiotics. ${ }^{69}$ Fifty three patients were divided into three groups: group I (16 patients who were referred more than eight days after disease onset) received intravenous nafamostat and antibiotics; group II (22 patients referred within seven days) received nafamostat via CRAI, and antibiotics intravenously; group III (15 patients referred within seven days) received both nafamostat and imipenem via CRAI. The incidence of infection of pancreatic necrosis in group III $(0 \%)$ was significantly lower than in groups I $(50 \%)$ and II $(22.8 \%)$. The mortality rates in groups II $(13.6 \%)$ and III $(6.7 \%)$ were significantly reduced, compared with that in group I $(43.8 \%)$, but were not significantly different from each other. The major drawbacks of this study are its uncontrolled, nonrandomised design, the use of different antibiotics, the short duration of antibiotic infusion, the clinically difficult technique, and the simultaneous use of a protease inhibitor, which may have complicated interpretation of the results. Therefore, further studies are necessary to evaluate the role of intra-arterial regional antibiotic treatment in severe acute pancreatitis.

\section{Treatment of infected pancreatic necrosis}

Local infection of necrotic areas of the pancreas influences the course of the disease, the prognosis, and the clinical management. Bacterial infection of pancreatic necrosis is usually suspected in patients who develop signs of sepsis, 
and is confirmed by a bacteriologically positive fine needle aspiration. Conservative treatment will lead to almost $100 \%$ mortality in patients with signs of local and systemic septic complications. ${ }^{367071}$ Even after surgery, infected necrosis carries a mortality rate (ranging from 15 to $82 \%$ ) which is three times higher than the mortality of sterile necrosis. $^{72} 73$ Infected pancreatic necrosis is a clear indication for surgery, but the management of sterile pancreatic necrosis is controversial. Over the past two decades, most surgical centres have adopted a very aggressive surgical approach to severe acute pancreatitis. However, there is now a growing trend towards treating patients with sterile severe acute pancreatitis conservatively. Surgical intervention may be limited to patients with a deteriorating clinical course which does not respond to intensive care. ${ }^{3674-76}$ However, it should be noted that valid criteria for surgical intervention in patients with sterile necrosis is still undetermined and under discussion.

Nevertheless, there is general agreement that surgical treatment of severe acute pancreatitis should be postponed for as long as possible, and the second or third week seems to guarantee optimal operative conditions for necrosectomy. Surgical methods for the treatment of necrosis are varied and the best method has yet to be determined. The recommended, and currently accepted, surgical management technique should be an organ preserving approach which involves debridement or necrosectomy, combined with a postoperative management concept that maximises evacuation of retroperitoneal debris and exudate. Three comparable techniques are available: $(a)$ closed continuous lavage of the retroperitoneum ${ }^{77}{ }^{78}$; (b) management by planned, staged re-laparotomy ${ }^{79}$; and (c) the open packing technique. ${ }^{80}$ In experienced hands these approaches have reduced mortality from severe acute pancreatitis to $<15 \%$.

Unproved strategies include percutaneous CT guided catheter drainage, recently described by Freeny and colleagues $^{81}$; transoral intrapancreatic drainage and irrigation lavage reported by Baron et $a l,^{82}$ and laparoscopic necrosectomy. ${ }^{83}$ Further evaluation of these techniques is needed before they can be adopted into clinical practice.

The authors wish to acknowledge Mark Kidd for his help in the preparation of this manuscript.

S W SCHMID

W UHL

H FRIESS

Department of Visceral and Transplantation Surgery, University Hospital of Bern, CH-3010 Bern, Switzerland

P MALFERTHEINER

Department of Gastroenterology, Hepatology and Infectious Disease, Otto-von Guericke-Universität, Leipziger Strasse 44, D-39120 Magdeburg, Germany

M W BÜCHLER

Department of Visceral and Transplantation Surgery, University Hospital of Bern, CH-3010 Bern, Switzerland

Correspondence to: Dr Büchler (email: markus.buechler@insel.ch).

1 Uhl W, Schrag HJ, Schmitter N, et al. Pathophysiological role of secretory type I and II phospholipase A2 in acute pancreatitis: an experimental study in rats. Gut 1997;40:386-92.

2 Uhl W, Isenmann R, Büchler MW. Infections complicating pancreatitis: diagnosing, treating, preventing. New Horizons 1998;6:S72-9.

3 Rattner DW, Legermate DA, Lee MJ, et al. Early surgical debridement of symptomatic pancreatic necrosis is beneficial irrespective of infection. $A m \mathcal{F}$ Surg 1992;163:105-9.

4 Renner IG, Savage WT, Pantoja JL, et al. Death due to acute pancreatitis. A retrospective analysis of 405 autopsy cases. Dig Dis Sci 1985;30:1005-18.

5 Beger HG, Bittner R, Block S, et al. Bacterial contamination of pancreatic necrosis. A prospective clinical study. Gastroenterology 1986;91:433-8.

6 Büchler M, Malfertheiner P, Uhl W, et al. Gabexate mesilate in human acute pancreatitis. German Pancreatitis Study Group. Gastroenterology 1993;104: pancreatitis.

7 Schmid S, Uhl W, Büchler MW. Protease-antiprotease interactions and the rationale for therapeutic protease inhibitors. Scand F Gastroenterol 1996;219 (suppl):47-50.
8 Uhl W, Büchler MW, Malfertheiner P, et al. A randomised, double-blind, multicentre trial of octreotide in moderate to severe acute pancreatitis. Gut 1999;45:97-104.

9 Lange JF, van Gool J, Tytgat GN. The protective effect of a reduction in intestinal flora on mortality of acute haemorrhagic pancreatitis in the rat. Hepatogastroenterology 1987;34:28-30.

10 Webster MW, Pasculle AW, Myerowitz RL, et al. Postinduction bacteremia in experimental acute pancreatitis. Am F Surg 1979;138:418-20.

11 Widdison AL, Karanjia ND, Reber HA. Routes of spread of pathogens into the pancreas in a feline model of acute pancreatitis. Gut 1994;35:1306-10.

12 Tarpila E, Nystrom PO, Franzen L, et al. Bacterial translocation during acute pancreatitis in rats. Eur F Surg 1993;159:109-13.

13 Marotta F, Geng TC, Wu CC, et al. Bacterial translocation in the course of acute pancreatitis: beneficial role of nonabsorbable antibiotics and lactitol enemas. Digestion 1996;57:446-52.

14 Runkel NS, Moody FG, Smith GS, et al. The role of the gut in the development of sepsis in acute pancreatitis. F Surg Res 1991;51:18-23.

15 Runkel NS, Rodriguez LF, Moody FG. Mechanisms of sepsis in acute pancreatitis in opossums. Am f Surg 1995;169:227-32.

16 Arendt T, Nizze H, Stuber E, et al. Infected bile-induced acute pancreatitis in rabbits. The role of bacteria. Int f Pancreatol 1998;24:111-16.

17 Byrne JJ, Joison J. Bacterial regurgitation in experimental pancreatitis. Am $\mathcal{F}$ Surg 1964;107:18-23.

18 Uhl W, Schrag HJ, Wheatley AM, et al. The role of infection in acute pancreatitis. Dig Surg 1994;11:214-19.

19 Widdison AL, Karanjia ND, Reber HA. Routes of spread of bacteria to the pancreas in acute necrotizing pancreatitis [abstract]. Pancreas 1990;5: A736.

20 Medich DS, Lee TK, Melhem MF, et al. Pathogenesis of pancreatic sepsis. Am F Surg 1993;165:46-50.

21 Arendt T, Wendt M, Olszewski M, et al. Cerulein-induced acute pancreatitis in rats: does bacterial translocation occur via a transperitoneal pathway? Pancreas 1997;15:291-6.

22 Border JR, Hassett J, LaDuca J, et al. The gut origin septic states in blunt multiple trauma (ISS = 40) in the ICU. Ann Surg 1987;206:427-48.

23 Sedman PC, Macfie J, Sagar P, et al. The prevalence of gut translocation in humans. Gastroenterology 1994;107:643-9.

24 Luiten EJ, Hop WC, Endtz HP, et al. Prognostic importance of Gram-negative intestinal colonization preceding pancreatic infection in severe acute pancreatitis. Results of a controlled clinical trial of selective decontamination. Intensive Care Med 1998;24:438-45.

25 Bradley EL 3d. A clinically based classification system for acute pancreatitis. Summary of the International Symposium on Acute Pancreatitis, Atlanta, Ga, September 11 through 13, 1992. Arch Surg 1993;128:586-90.

26 Gerzof SG, Banks PA, Robbins AH, et al. Early diagnosis of pancreatic infection by computed tomography-guided aspiration. Gastroenterology 1987;93:1315-20.

27 Bassi C, Falconi M, Girelli R, et al. Microbiological findings in severe acute pancreatitis. Surg Res Commun 1989;5:1-4.

28 Banks PA. Infected necrosis: morbidity and therapeutic consequences. Hepatogastroenterology 1991;38:116-19.

29 Uhl W, Büchler M, Malfertheiner P, et al. PMN-elastase in comparison with CRP, antiproteases, and LDH as indicators of necrosis in human acute pancreatitis. Pancreas 1991;6:253-9.

30 Schmid SW, Uhl W, Steinle A, et al. Human pancreas-specific protein. A diagnostic and prognostic marker in acute pancreatitis and pancreas transplantation. Int $\mathcal{7}$ Pancreatol 1996;19:165-70.

31 Beger HG, Büchler M, Bittner R, et al. Necrosectomy and postoperative local lavage in necrotising pancreatitis. Br f Surg 1988;75:207-12.

32 Isenmann R, Büchler M, Uhl W, et al. Pancreatic necrosis: an early finding in severe acute pancreatitis. Pancreas 1993;8:358-61.

33 Schwarz $M$, Büchler $M$, Thomsen J, et al. Pancreatic infection in experimental acute pancreatitis: a frequent finding [abstract]. Digestion 1993;54:A119.

34 Wells CL. Colonization and translocation of intestinal bacterial flora. Transplant Proc 1996;28:2653-6.

35 Luiten EJ, Hop WC, Lange JF, et al. Controlled clinical trial of selective decontamination for the treatment of severe acute pancreatitis. Ann Surg 1995;222:57-65.

36 Widdison AL, Karanjia ND. Pancreatic infection complicating acute pancreatitis. Br F Surg 1993;80:148-54.

37 Bradley EL 3d. Operative management of acute pancreatitis: ventral open packing. Hepatogastroenterology 1991;38:134-8.

38 Pederzoli P, Bassi C, Vesentini S, et al. Retroperitoneal and peritoneal drainage and lavage in the treatment of severe necrotizing pancreatitis. Surg Gynecol Obstet 1990;170:197-203.

39 Banks PA, Gerzof SG, Langevin RE, et al. CT-guided aspiration of suspected pancreatic infection: bacteriology and clinical outcome. Int $\mathcal{F}$ Pancreatol 1995; 18:265-70.

40 Farkas G, Marton J, Mandi Y, et al. Surgical strategy and management of infected pancreatic necrosis. Br F Surg 1996;83:930-3.

41 Luiten EJ, Hop WC, Lange JF, et al. Differential prognosis of Gram-negative versus Gram-positive infected and sterile pancreatic necrosis: results of a versus Gram-positive infected and sterile pancreatic necrosis: results of a adjuvant selective decontamination. Clin Infect Dis 1997;25:811-16.

42 Craig RM, Dordal E, Myles L. The use of ampicillin in acute pancreatitis [letter]. Ann Intern Med 1975;83:831-2.

43 Howes R, Zuidema GD, Cameron JL. Evaluation of prophylactic antibiotics in acute pancreatitis. F Surg Res 1975;18:197-200.

44 Finch WT, Sawyers JL, Schenker S. A prospective study to determine the efficacy of antibiotics in acute pancreatitis. Ann Surg 1976;183:667-71.

45 Büchler M, Malfertheiner P, Friess H, et al. Human pancreatic tissue concentration of bactericidal antibiotics. Gastroenterology 1992;103:19028 .

46 Bassi C, Pederzoli P, Vesentini S, et al. Behavior of antibiotics during human necrotizing pancreatitis. Antimicrob Agents Chemother 1994;38:830-6.

47 Burns GP, Stein TA, Kabnick LS. Blood-pancreatic juice barrier to antibiotic excretion. Am F Surg 1986;151:205-8.

48 Pederzoli P, Bassi C, Vesentini S, et al. A randomized multicenter clinical trial of antibiotic prophylaxis of septic complications in acute necrotizing pancreatitis with imipenem. Surg Gynecol Obstet 1993;176:480-3.

49 Sainio V, Kemppainen E, Puolakkainen P, et al. Early antibiotic treatment in acute necrotising pancreatitis. Lancet 1995;346:663-7. 
50 Delcenserie R, Yzet T, Ducroix JP. Prophylactic antibiotics in treatment of severe acute alcoholic pancreatitis. Pancreas 1996;13:198-201.

51 Schate alcoholic pancreatitis. Pancreas 1996,13:198-201. creatitis. Results of a controlled study. Dtsch Med Wochenschr 1997;122: $356-61$.

52 Bassi C, Falconi M, Talamini G, et al. Controlled clinical trial of pefloxacin versus imipenem in severe acute pancreatitis. Gastroenterology 1998;115 1513-17.

53 Foitzik T, Fernandez-del Castillo C, Ferraro MJ, et al. Pathogenesis and prevention of early pancreatic infection in experimental acute necrotizing pancreatitis. Ann Surg 1995;222:179-85.

54 Golub R, Siddiqi F, Pohl D. Role of antibiotics in acute pancreatitis: a metaanalysis. F Gastrointest Surg 1998;2:496-503.

55 Ho HS, Frey CF. The role of antibiotic prophylaxis in severe acute pancreatitis. Arch Surg 1997;132:487-92.

56 Barie PS. A critical review of antibiotic prophylaxis in severe acute pancreatitis. Am f Surg 1996;172:38S-43S.

57 Powell JJ, Miles R, Siriwardena AK. Antibiotic prophylaxis in the initial management of severe acute pancreatitis. Br f Surg 1998;85:582-7.

58 Stoutenbeek CP, van Saene HK, Miranda DR, et al. The effect of selective decontamination of the digestive tract on colonisation and infection rate in decontamination of the digestive tract on colonisation and infect
multiple trauma patients. Intensive Care Med 1984;10:185-92.

59 Tetteroo GW, Wagenvoort JH, Ince C, et al. Effects of selective decontamination on Gram-negative colonisation, infections and development of bacterial resistance in esophageal resection. Intensive Care Med 1990;16:S2248 .

60 Cerra FB, Maddaus MA, Dunn DL, et al. Selective gut decontamination reduces nosocomial infections and length of stay but not mortality or organ failure in surgical intensive care unit patients. Arch Surg 1992;127:163-7.

61 Rocha LA, Martin MJ, Pita S, et al. Prevention of nosocomial infection in critically ill patients by selective decontamination of the digestive tract. A randomized, double blind, placebo-controlled study. Intensive Care Med 1992;18:398-404.

62 Gastinne $\mathrm{H}$, Wolff $\mathrm{M}$, Delatour F, et al. A controlled trial in intensive care units of selective decontamination of the digestive tract with nonabsorbable antibiotics. The French Study Group on Selective Decontamination of the Digestive Tract. N Engl f Med 1992;326:594-9.

63 Isaji S, Suzuki M, Frey CF, et al. Role of bacterial infection in diet-induced acute pancreatitis in mice. Int f Pancreatol 1992;11:49-57.

64 Gianotti L, Munda R, Gennari R, et al. Effect of different regimens of gut decontamination on bacterial translocation and mortality in experimental decontamination on bacterial translocation an

65 McClelland P, Murray A, Yaqoob M, et al. Prevention of bacterial infection and sepsis in acute severe pancreatitis. Ann R Coll Surg Engl 1992;74:32934

66 Blamey SL, Imrie CW, O’Neill J, et al. Prognostic factors in acute pancreatitis. Gut 1984;25:1340-6.
67 Balthazar EJ, Ranson JH, Naidich DP, et al. Acute pancreatitis: prognostic value of CT. Radiology 1985;156:767-72.

68 Hayashi J, Kawarada Y, Isaji S, et al. Therapeutic effects of continuous intraarterial antibiotic infusion in preventing pancreatic infection in experimental acute necrotizing pancreatitis. Pancreas 1996;13:184-92.

69 Takeda K, Matsuno S, Sunamura M, et al. Continuous regional arterial infusion of protease inhibitor and antibiotics in acute necrotizing pancreatitis. Am $\mathcal{F}$ Surg 1996;171:394-8.

70 Beger HG, Büchler M. Decision-making in surgical treatment of acute pancreatitis: operative or conservative management of necrotizing pancreatitis? Theoretical Surg 1986;1:61-8.

71 Bradley EL 3d. Antibiotics in acute pancreatitis. Current status and future directions. Am F Surg 1989;158:472-7.

72 Beger HG, Rau B, Mayer J, et al. Natural course of acute pancreatitis. World 7 Surg 1997;21:130-5.

73 D'Egidio A, Schein M. Surgical strategies in the treatment of pancreatic necrosis and infection. Br F Surg 1991;78:133-7.

74 Isenmann R, Büchler MW. Infection and acute pancreatitis. BrF Surg 1994; 81:1707-8.

75 Bradley EL 3d, Allen K. A prospective longitudinal study of observation versus surgical intervention in the management of necrotizing pancreatitis. Am F Surg 1991;161:19-24.

76 Büchler M, Uhl W, Beger HG. Surgical strategies in acute pancreatitis. Hepatogastroenterology 1993;40:563-8.

77 Büchler M, Uhl W, Isenmann $\mathrm{R}$, et al. Necrotizing pancreatitis: necrosectomy and closed continuos lavage of the lesser sac. The Ulm experience. In: Beger HG, Büchler M, Malfertheiner P, eds. Standards in pancreatic surgery. Berlin, Heidelberg: Springer Verlag, 1993.

78 Larvin M, Chalmers AG, Robinson PJ, et al. Debridement and closed cavity irrigation for the treatment of pancreatic necrosis. Br f Surg 1989;76:46571.

79 Sarr MG, Nagorney DM, Mucha P Jr, et al. Acute necrotizing pancreatitis: management by planned, staged pancreatic necrosectomy/debridement and delayed primary wound closure over drains. Brf Surg 1991;78:576-81.

80 Bradley EL 3d. A fifteen year experience with open drainage for infected pancreatic necrosis. Surg Gynecol Obstet 1993;177:215-22.

81 Freeny PC, Hauptmann E, Althaus SJ, et al. Percutaneous CT-guided catheter drainage of infected acute necrotizing pancreatitis: techniques and results. AfR Am f Roentgenol 1998;170:969-75.

82 Baron TH, Thaggard WG, Morgan DE, et al. Endoscopic therapy for organized pancreatic necrosis. Gastroenterology 1996;111:755-64.

83 Cuschieri SA, Jakimowicz JJ, Stultiens G. Laparoscopic infracolic approach for complications of acute pancreatitis. Semin Laparosc Surg 1998;5:18994 